\title{
Public Willingness and Hesitancy to Take the COVID-19 Vaccine in Afghanistan
}

\author{
Arash Nemat, ${ }^{1,2 \star}$ Ayesha Bahez, ${ }^{1}$ Mohibullah Salih, ${ }^{1}$ Nahid Raufi, ${ }^{3,4}$ Noor Ahmad Shah Noor, ${ }^{5}$ Mohammad Yasir Essar, ${ }^{5,6}$ \\ Ehsanullah Ehsan, ${ }^{7}$ and Abdullah Asady ${ }^{1}$ \\ ${ }^{1}$ Department of Microbiology, Kabul University of Medical Sciences, Kabul, Afghanistan; ${ }^{2}$ Department of Cardiology, Nanfang Hospital, Southern \\ Medical University, Guangzhou, China; ${ }^{3}$ Department of Dermatology, Kabul University of Medical Sciences, Kabul, Afghanistan; ${ }^{4}$ Department of \\ Dermatology, Guangdong Provincial Dermatology Hospital, Southern Medical University, Guangzhou, China; ${ }^{5}$ Faculty of Dentistry, Kabul University \\ of Medical Sciences, Kabul, Afghanistan; ${ }^{6}$ Medical Research Center, Kateb University, Kabul, Afghanistan; ${ }^{7}$ Department of Dermatology, Alberoni \\ University, Kapisa, Afghanistan
}

\begin{abstract}
COVID-19 has been causing a global threat to almost all countries for more than one year. Vaccination of the majority of any country's population is considered to be an effective way of controlling the spread and mortality of this infection. Therefore, it is important to assess the public's willingness to be vaccinated against COVID-19. In this study, we evaluated the public willingness and hesitancy to take the vaccine in Afghanistan, during December 2020 and January 2021. Sociodemographic data, awareness on vaccine production, vaccine availability, willingness and hesitancy to take the COVID-19 vaccine were collected. The Statistical Package for Social Studies (SPSS) version 25 was used for data analysis. A total of 806 complete responses were received. Majority of the respondents were $\leq 40$ years old $(89.8 \%)$ and male $(72.7 \%)$. Less than two-thirds $(509 ; 63 \%)$ of the participants reported willingness to take the vaccine when it becomes available, whereas almost one-third (297; 37\%) of them were hesitant to take the COVID-19 vaccine. More female than male respondents were willing to take the vaccine $\left(\chi^{2}=13.176, P\right.$ value $\left.=0.001\right)$. A significant portion of the public were not willing to take the COVID-19 vaccine. In a country like Afghanistan, which already has a low coverage of vaccination, this could pose a challenge for the vaccination program against COVID-19 to be effective. The Ministry of Public Health should work on public trust and change people's mindset about vaccine reality and efficacy to prevent the rejection of this health intervention.
\end{abstract}

\section{INTRODUCTION}

COVID-19 caused by Severe Acute Respiratory Coronavirus2 (SARS-CoV-2) first emerged in Wuhan, China. ${ }^{1}$ Since its emergence, it has spread to almost every country around the globe and has been declared as a pandemic by the World Health Organization (WHO). ${ }^{2}$ Globally, as of February 9, 2021, there have been 106,125,682 confirmed cases of COVID-19, including 2,320,497 deaths, were reported to $\mathrm{WHO}^{3}$

Afghanistan, like most countries, was hit hard by the relentless spread of corona virus, ${ }^{4}$ especially as the healthcare system of this war-torn country was already overburdened before. $^{5}$ In Afghanistan, the first case of COVID-19 was reported on February 24, 2020, in a 35-year-old man who had recently visited Qom, Iran. ${ }^{6}$ As of February 1, 2021, there were 55,121 confirmed cases with 2,405 death reports. ${ }^{7}$ Very likely the actual figures may exceed those reported. ${ }^{6}$

The best way to control the spread, and socioeconomic consequences at any level of any infectious disease for which there is not effective treatment to mitigate its burden, is to have an effective vaccine to deactivate it. ${ }^{8}$ Having a safe vaccine at hand will alleviate the sufferings associated with communicable diseases and enable people to regain normalcy in their lives. Hence, the availability of a secure and safe vaccine is of high importance in the current pandemic. Since the declaration of COVID-19 pandemic, there has been a race for the development a safe and effective vaccine against SARS-CoV-2. As of January 22, 2021, 64 vaccines were in clinical development and 173 vaccine candidates were in preclinical evaluation. ${ }^{9}$

Considering the fact that having an effective and safe vaccine is the only perceived intervention to limit the current pandemic, this can be effective only if and when there is less hesitancy against taking the vaccine. Vaccine hesitancy refers

*Address correspondence to Arash Nemat, Department of Microbiology, Kabul University of Medical Sciences, Kabul, Afghanistan. E-mail: dr.arashnemat@yahoo.com. to delay in acceptance or refusal of vaccination despite availability of vaccination services. It is classified as one of the top 10 public health issues by WHO in $2019 .{ }^{10}$ Recently, there has been a continuous decline in vaccine coverage and an increase in the incidents of vaccine-preventable diseases, such as a $30 \%$ increase in global cases of measles. Vaccine hesitancy is considered a major contributor to this. ${ }^{10}$

Vaccine hesitancy is a complex phenomenon and context specific, varying across time, place, and vaccines. Factors such as complacency, convenience, and confidence are reported to have influence on vaccine hesitancy. ${ }^{11}$ Meanwhile, vaccine hesitancy has been defined as a set of beliefs, attitudes, or behaviors, or a combination of them, shared by a large and heterogeneous section of the population and including people who exhibit reluctant conformism, and vaccinespecific behaviors. ${ }^{12}$

Different conceptual models have been proposed to address the complexity, applicability, and potential usefulness of vaccine hesitancy indicators, as well as for the design of surveys and interventions that can be applied locally and globally. One of the most useful suggestions is the "Three Cs" model of vaccine confidence, complacency, and convenience, given that it is intuitive and easy to understand and apply. ${ }^{11}$

In Afghanistan with its already low general coverage of vaccination, that is, $39 \%$, people's willingness and hesitancy toward COVID-19 vaccine is of particular importance. ${ }^{13}$ To make sure the vaccination efforts succeed and the coverage required to reach herd immunity will be achieved, policy makers need to be informed about public willingness to take the COVID-19 vaccine. Therefore, this study aims to evaluate the willingness and hesitancy of Afghanistan population toward the COVID-19 vaccine.

\section{MATERIALS AND METHODS}

Study design and setting. An online survey was conducted among the public in Afghanistan during December 
2020 and January 2021. We used a non-probability convenient sampling technique to recruit the respondents, who were asked to fill out the questionnaire within the period stipulated for the study as used in previous studies. ${ }^{14,15}$ Potential participants were invited from across the country, including major cities such as Kabul, Herat, Balkh, Qandahar, and Nangarhar. The survey link was shared through Facebook, WhatsApp, and Telegram channels. The primary participants were requested to roll down the survey further. On receiving and clicking the link, the participants were directed to the informed consent page, followed by the survey questionnaire. People who had access to the Internet, were social media users, and consented to participate in the study were included in the survey, whereas, those who did not consent to take part in the study were excluded.

Questionnaire development. The key areas to include in this survey were identified using the data from similar published studies, ${ }^{14,16-18}$ and a draft questionnaire was devised. The content validation of the draft questionnaire was performed by three research experts at Kabul University of Medical Sciences, Kabul, Afghanistan, and it was modified as per their comments. Then, the modified draft of the survey went through pilot testing on 30 randomly selected participants to make sure it was readable and understandable. The participants did not have any comments to be considered. The survey questionnaire was bilingual (Persian and English) and consisted of sections on sociodemographics, knowledge, hesitancy, and willingness of the participants to take the COVID-19 vaccine when it becomes available. We tried to keep the questionnaire as short as possible so that it was quick to complete, and easy to follow.

Measures. The survey included the following measures, some of which were dichotomized for analysis: age (18-40 years and more than 40 years), gender (female and male), employment status (used and unemployment), education (preuniversity and university), and location (Kabul and other provinces). Moreover, respondents self-reported on their knowledge about any COVID-19 vaccine that has been produced worldwide (Yes/know versus No/don't know). In addition, participants indicated their responses to question "Can Afghan government provide the COVID-19 vaccine to its citizens during the year 2021?" by choosing (Yes or No). Willingness to receive a COVID-19 vaccine was assessed with the following item: "If a vaccine becomes available for COVID19 , would you take it?" the respondents were asked to indicate with an Yes or No response. If a participant indicated (Yes) option, the survey would end and prepared for submission, but if someone indicated the negative option (No), the questionnaire would further ask for reasons for not taking the vaccine. In this part, multiple reasons could be selected, they were highlighted as the main reasons of vaccine hesitancy in previously published articles. ${ }^{14,19-21}$ "It is not safe," "my immune system is sufficient to combat against COVID-19 infection," "COVID-19 is not real," "I do not trust the clinical trials," "the vaccine contains a chip that will track me," and "it may cause infertility" were the items included in this section.

Data analysis. The data were coded and entered into a Microsoft Excel spreadsheet and then entered into the Statistical Package for Social Studies (SPSS) version 25 for analysis. Simple descriptive analysis was computed for demographic characteristics. Intention to take vaccine, reservations toward vaccination, and availability of vaccine in Afghanistan and the reasons for nonacceptance of the COVID-19 vaccine were presented using bar graphs. Bi-variable (chi-square) analysis was carried out to find out associations of willingness to take the COVID-19 vaccine with age groups, gender, education level, and geographical locations. A $P$ value of $<0.05$ was considered significant at $95 \%$ confidence interval.

\section{RESULTS}

Table 1 presents the sociodemographic characteristics of the study participants. Almost three quarters (73\%) were male respondents. Nearly $90 \%$ of them were $\leq 40$ years old. The majority (81\%) of the participants had university education and two-thirds were living in Kabul, the capital of Afghanistan. Only half of the participants reported to be used (either in the public or private sector) and the remaining reported to be unused (Table 1).

Responses to the questions on awareness, availability, willingness, and hesitancy to take the COVID-19 vaccine are illustrated in Figure 1.

As shown in the table, the majority of participants (88\%) reported their awareness on production of the COVID-19 vaccine, and only one in five of them were thinking that the government of Afghanistan would be able to provide the vaccine for its people during 2021 . Slightly less than two-thirds (63\%) of the subjects were willing to take the COVID-19 vaccine if and when it is available, and $42 \%$ of them showed their reservations toward vaccination.

To investigate the association of age, gender, education level, and geographical locations with willingness to take the COVID-19 vaccine, $\chi^{2}$ analyses were conducted. The proportion of female respondents who were willing to receive the COVID-19 vaccine was significantly higher than that of the males $\left(\chi^{2}=13.176, P\right.$ value $\left.=0.001\right)$. However, other variables such as age group, education level, and geographical locations did not show any significant association with willingness to take the COVID-19 vaccine, as shown in Table 2.

The major reason to hesitate about taking the COVID-19 vaccine was their belief that the COVID-19 vaccine, which will be provided for low-income countries, might be of low quality $(43.2 \%)$, followed by the belief that "it is not safe" $(39.6 \%)$ and "I have sufficient immunity to combat against the virus" (25.4\%), as shown in Figure 2.

\section{DISCUSSION}

There has been a worldwide effort to produce an effective vaccine for SARS-CoV-2. ${ }^{22}$ Vaccination could be an effective strategy for slowing the spread of the current COVID-19

TABLE 1

Sociodemographic characteristics of the participants $(N=806)$

\begin{tabular}{llcc}
\hline & Characteristics & Frequency $(\mathrm{N})$ & Percentage (\%) \\
\hline Gender & Female & 220 & 27.3 \\
& Male & 586 & 72.7 \\
Age (years) & $\leq 40$ & 724 & 89.8 \\
& $>40$ & 82 & 10.2 \\
Education & University & 655 & 81.4 \\
& Preuniversity & 151 & 18.6 \\
Residence & Kabul (Capital) & 534 & 66.3 \\
& Other provinces & 272 & 33.7 \\
Occupation & Used & 407 & 50.4 \\
& Unused & 399 & 49.6 \\
\hline
\end{tabular}




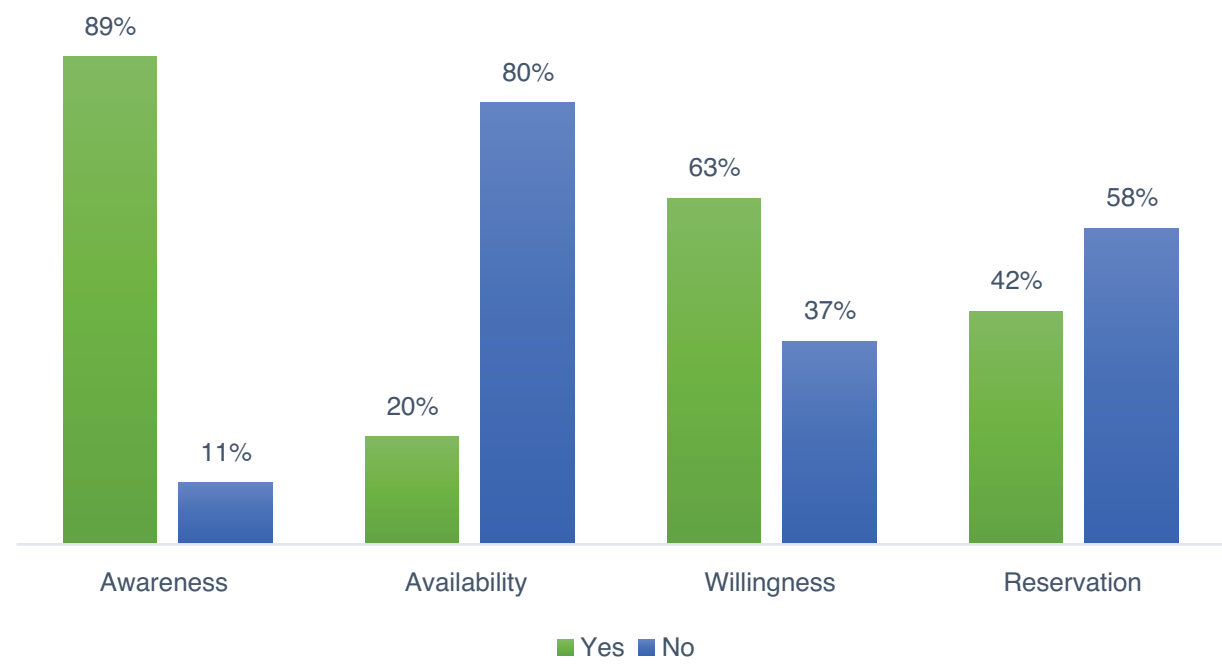

FIGURE 1. Percentage distribution of the responses on awareness, availability, willingness, and reservation toward COVID-19 vaccine. This figure appears in color at www.ajtmh.org.

pandemic. ${ }^{23}$ Vaccine hesitancy is an imminent threat in the battle against COVID-19. ${ }^{24}$ To reach herd immunity, this vaccine should be administered to a large part of any population, otherwise the fight for control of the spread and mortality of the COVID-19 may not be successful. Thus, it is important to know public perceptions and intentions toward the COVID-19 vaccine, so that the public health authorities have the time to come up with effective programs to increase public awareness about the importance of vaccination. In this context, we conducted the survey to investigate the public willingness and hesitancy toward COVID-19 vaccine in Afghanistan. To the best our knowledge, this is the first study of its type in Afghanistan, and the findings will provide a useful insight for policy makers in designing vaccination programs against COVID-19.
The majority of the participants $(88 \%)$ knew that there were efforts to develop vaccines for COVID-19. This shows that the public is interested and following the news and information spread on COVID-19. Only one out of five respondents were thinking that the government of Afghanistan would be able to provide the vaccine for its people during 2021. This might indicate that the public are conscious about the budget constraints, unstable security, and prevalent corruption potentially hindering the provision and distribution of the COVID-19 vaccine to Afghan people.

Almost two-thirds (63\%) of our subjects were willing to take the COVID-19 vaccine when it is available. This is lower than what is being reported from Brazil (88\%), China (85\%), Mexico (85\%), Italy (80\%), Spain (80\%), Canada (79\%), South Korea

TABLE 2

Association between selected sociodemographic variables, vaccine reservation, and COVID-19 vaccine acceptance

\begin{tabular}{|c|c|c|c|c|}
\hline \multirow[b]{2}{*}{$\begin{array}{l}\text { Variable } \\
N=806\end{array}$} & \multicolumn{2}{|c|}{$\begin{array}{c}\text { Do you have any reservations toward vaccination? } \\
\text { (Reservations toward vaccination) }\end{array}$} & \multicolumn{2}{|c|}{$\begin{array}{l}\text { Will you take COVID-19 vaccine? } \\
\text { (COVID-19 vaccine acceptance) }\end{array}$} \\
\hline & $\begin{array}{l}\text { Yes } \\
\mathrm{N}(\%)\end{array}$ & $\begin{array}{l}\text { No } \\
N(\%)\end{array}$ & $\begin{array}{l}\text { Yes } \\
N(\%)\end{array}$ & $\begin{array}{l}\mathrm{No} \\
\mathrm{N}(\%)\end{array}$ \\
\hline \multicolumn{5}{|l|}{ Gender } \\
\hline Female (220) & $84(38.2)$ & $136(61.8)$ & $170(77.3)$ & $50(22.7)$ \\
\hline \multirow[t]{2}{*}{ Male (586) } & $258(44.0)$ & $328(56.0)$ & $338(57.7)$ & $248(42.3)$ \\
\hline & \multicolumn{2}{|c|}{$\chi^{2}=1.119, P$ value $=0.290$} & \multicolumn{2}{|c|}{$\chi^{2}=13.176, P$ value $=0.000$} \\
\hline \multicolumn{5}{|l|}{ Age group (years) } \\
\hline$>40(82)$ & $36(43.9)$ & $46(56.1)$ & $48(58.5)$ & $34(41.5)$ \\
\hline \multirow[t]{2}{*}{$\leq 40(724)$} & $306(42.3)$ & $418(57.7)$ & $460(63.5)$ & $264(36.5)$ \\
\hline & \multicolumn{2}{|c|}{$\chi^{2}=00.040, P$ value $=0.841$} & \multicolumn{2}{|c|}{$\chi^{2}=00.395, P$ value $=0.530$} \\
\hline Used (407) & \multicolumn{4}{|c|}{ Occupation } \\
\hline \multirow{2}{*}{ Unemployed (399) } & $169(425)$ & $\begin{array}{l}235(5 / .6) \\
230(57.5)\end{array}$ & $\begin{array}{l}255(02.0) \\
253(635)\end{array}$ & $152(37.4)$ \\
\hline & \multicolumn{2}{|c|}{$\chi^{2}=00.001, P$ value $=0.987$} & \multicolumn{2}{|c|}{$\chi^{2}=0.038, P$ value $=0.845$} \\
\hline \multicolumn{5}{|c|}{ A } \\
\hline Kabul (534) & $202(37.8)$ & $332(62.2)$ & $350(65.5)$ & $184(34.5)$ \\
\hline \multirow[t]{2}{*}{ Other provinces (272) } & $140(51.5)$ & $132(48.5)$ & $158(58.1)$ & $114(41.9)$ \\
\hline & \multicolumn{2}{|c|}{$\chi^{2}=6.866, P$ value $=0.009$} & \multicolumn{2}{|c|}{$\chi^{2}=2.149, P$ value $=0.143$} \\
\hline \multicolumn{5}{|l|}{ Education } \\
\hline Pre-university (151) & $44(29.3)$ & $107(70.7)$ & $95(62.7)$ & 56 (37.3) \\
\hline \multirow[t]{2}{*}{ University (655) } & 297 (45.4) & $358(54.6)$ & $413(63.1)$ & $242(36.9)$ \\
\hline & \multicolumn{2}{|c|}{$\chi^{2^{\prime}}=6.472, P$ value $=0.011$} & \multicolumn{2}{|c|}{$\chi^{2}=0.005, P$ value $=0.943$} \\
\hline Total & $341(42.4 \%$ & 465 (57.6\%) & 509 (63\%) & 297 (37\%) \\
\hline
\end{tabular}




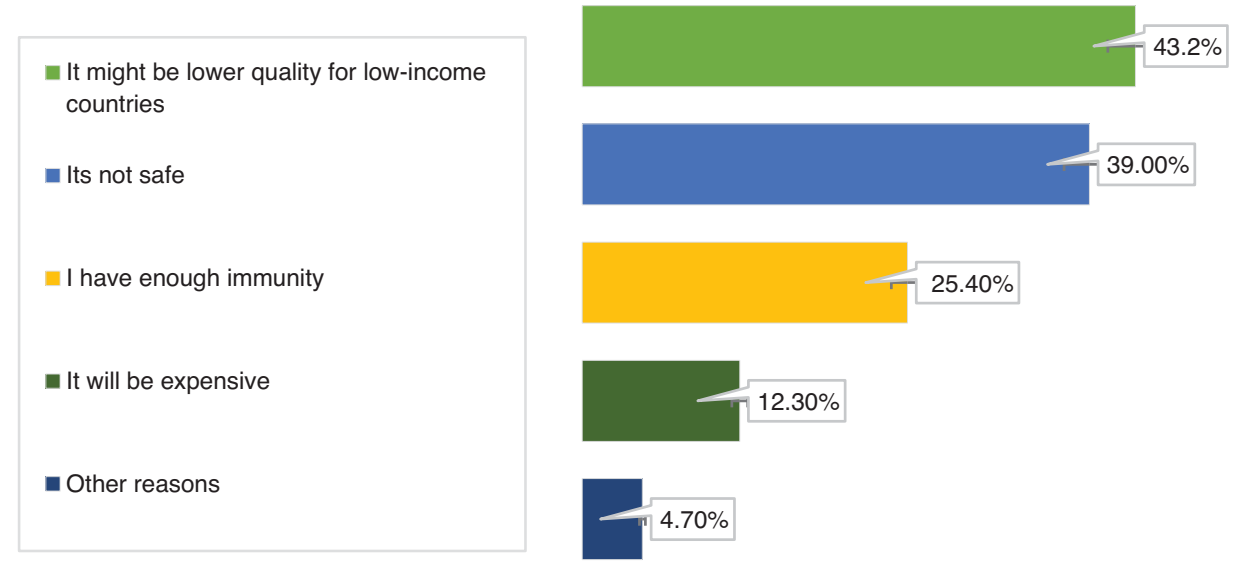

FIGURE 2. Reasons for reservation of COVID-19 vaccine by the respondents. This figure appears in color at www.ajtmh.org.

(78\%), Nigeria (74\%), Australia (73\%), the United States (71\%), and Germany (68\%). ${ }^{14,25}$ However, the willingness to take the COVID-19 vaccine in our study participants seems higher than what is reported from South Africa (61\%), France (57\%), and Russia (42\%). ${ }^{25}$

The proportion of female respondents willing to take the COVID-19 vaccine was significantly higher than that of males (77.3\% vs. $57.7 \%$; $P=0.001$ ). This contrasts with a European survey $^{18}$ and a systematic review of the COVID-19 vaccine acceptance, ${ }^{26}$ where the proportion of males willing to take the COVID-19 is reported higher than that of females. However, our finding conforms with a global survey on acceptance of the COVID-19 vaccine among 13,426 randomly selected individuals across 19 countries. $^{27}$ This finding might indicate that the female population may be less affected by the conspiratory theories compared with males. However, this trend may change as the number of female participants balanced against males in future studies. No significant association was found between the age groups and willingness to take the COVID-19 vaccine. This also contrasts with a study conducted among Nigerian public. ${ }^{14}$

More than one-third (37\%) of our participants were not willing to take the COVID-19 vaccine. This is higher than what is reported from Nigeria (25\%), ${ }^{14}$ Saudi Arabia (16\%), Malaysia (15\%), India (13\%), Brazil (12\%), and China (3\%), according to a World Economic Forum's global survey. ${ }^{25}$ However, reports from Russia (47\%), Poland (45\%), Hungary $(44 \%)$, and France $(41 \%)^{14}$ are higher than that of our study. This population can influence others with their negative perception of the COVID-19 vaccine leading to more people refusing the vaccine. This, in turn, it could pose a challenge to reach herd immunity to curb the COVID-19 infection in Afghanistan. Therefore, awareness campaigns should be targeted towards them to change their mindsets about the COVID-19 vaccine.

The reasons for nonacceptance of the COVID-19 vaccine among the study participants were assumed low quality of the vaccine, having sufficient immunity to combat COVID-19, and that the COVID-19 vaccine was not safe. Similar reasons have been reported to cause hesitancy among public in Nigeria, ${ }^{14}$ Brazil, and Japan. ${ }^{25}$ It is also being reported that vaccine adoption is a sum of vaccine access and acceptance. As our study indicated that four out of five participants had doubts about availability of COVID-19 vaccine in Afghanistan during
2021. This sense of nonavailability might also have contributed to hesitancy toward the COVID-19 vaccine.

Limitations. The survey results should not be generalized because the pattern of questionnaire distribution may influence the outcome. We used the social media platform to reach the respondents and many citizens who lived in districts, people from lower socioeconomic classes, people with lack/lower level of education, and old-age groups may not have been able to participate in this survey, because the general public in Afghanistan have minimal access to the Internet and social media. Therefore, the findings of this study may not reflect the willingness and hesitancy of the general Afghan population. Moreover, acceptance was assessed at the time when the vaccine was not yet available, which may differ from the respondents' preferences when the vaccine becomes available.

\section{CONCLUSION}

In this survey, we report that less than two-thirds of the Afghan public were willing to take the COVID-19 vaccine with a significant portion having reservations to take it. The negative thoughts of those who were not willing to take the vaccine could influence others and pose a challenge to the implementation the COVID-19 vaccination program targeting the whole population. Hence, the Afghan Ministry of Public Health should target these individuals through awareness campaigns to prevent the negative influence of their thoughts on other people. Besides, the Afghan Ministry of Public Health needs to ensure that the implications of the vaccine are equitable when it becomes available.

Received February 24, 2021. Accepted for publication May 29, 2021. Published online July 8, 2021.

Acknowledgments: We would like to sincerely thank PD Dr. Silvia Kaeppeli for editing this manuscript. The American Society of Tropical Medicine and Hygiene has waived the Open Access fee for this article due to the ongoing COVID-19 pandemic and has assisted with publication expenses.

Financial support: This research received no external funding.

Disclaimer: Ethical approval was obtained from Department of Microbiology, Kabul University of Medical Sciences. Respondents' participation was completely consensual, anonymous, and voluntary.

Authors' addresses: Arash Nemat, Department of Microbiology, Kabul University of Medical Sciences, Kabul, Afghanistan, and Department of 
Cardiology, Nanfang Hospital, Southern Medical University, Guangzhou, China, E-mail: dr.arashnemat@yahoo.com. Ayesha Bahez, Mohibullah Salih, and Abdullah Asady, Department of Microbiology, Kabul University of Medical Sciences, Kabul, Afghanistan, E-mails: ayeshabahez@gmail.com, mohibullahsalih786@gmail. com, and asady.abdullah@yahoo.com. Nahid Raufi, Department of Dermatology, Kabul University of Medical Sciences, Kabul, Afghanistan, and Department of Dermatology, Guangdong Provincial Dermatology Hospital, Southern Medical University, Guangzhou, China, E-mail: dr.nahidraufi111@gmail.com. Mohammad Yasir Essar, Faculty of Dentistry, Kabul University of Medical Sciences, Afghanistan, E-mail: yasir.essar@gmail.com. Noor Ahmad Shah Noor, Department of Oral and Maxillofacial Surgery, Kabul University of Medical Sciences, Afghanistan, E-mail: dnoorahmad0@gmail.com. Ehsanullah Ehsan, Department of Dermatology, Alberoni University, Kapisa, Afghanistan, E-mail: ehsanullah.ansari2@gmail.com.

This is an open-access article distributed under the terms of the Creative Commons Attribution (CC-BY) License, which permits unrestricted use, distribution, and reproduction in any medium, provided the original author and source are credited.

\section{REFERENCES}

1. Liu Y-C, Kuo R-L, Shih S-R, 2020. COVID-19: the first documented coronavirus pandemic in history. Biomed $\mathrm{J}$ 43: 328333.

2. Zhu W Chen CZ, Gorshkov K, Xu M, Lo DC, Zheng W, 2020. RNAdependent RNA polymerase as a target for COVID-19 drug discovery. SLAS Discov 25: 1141-1151.

3. World Health Organization, 2021. WHO Coronavirus Disease (COVID-19) Dashboard. Available at: https://covid19.who.int/ ?gclid=CjOKCQiApY6BBhCsARIsAOI_GjYNu6p2pl4ULbPftmm usZBtL1XKCYvL-MOHMZVGg7zF4zk1ncX-be0aAgJ2EALw_ wcB Accessed February 9, 2021.

4. Lucero-Prisno DE III, Ahmadi A, Essar MY, Lin X, Adebisi YA, 2020. Addressing COVID-19 in Afghanistan: what are the efforts and challenges? J Glob Health 10: 020341.

5. Lucero-Prisno DE, Essar MY, Ahmadi A, Lin X, Adebisi YA, 2020. Conflict and COVID-19: a double burden for Afghanistan's healthcare system. Confl Health 14: 65.

6. Nemat A, Asady A, Raufi N, Zaki N, Ehsan E, Noor NAS, Zeng Q, 2020. A survey of the healthcare workers in Afghanistan during the COVID-19 pandemic. Am J Trop Med Hyg. doi: 10.4269/ ajtmh.20-1367.

7. World Meter, 2021. Afghanistan, Coronavirus Cases. Available at https://www.worldometers.info/coronavirus/country/ afghanistan/. Accessed February 1, 2021.

8. Murphy $\mathrm{J}$ et al., 2021. Psychological characteristics associated with COVID-19 vaccine hesitancy and resistance in Ireland and the United Kingdom. Nat Commun 12: 1-15.

9. World Health Organization, 2021. Draft Landscape and Tracker of COVID-19 Candidate Vaccines. Available at: https://www.who. int/publications/m/item/draft-landscape-of-covid-19-candidatevaccines. Accessed January 26, 2021.

10. World Health Organization, 2021. Ten Threats to Global Health in 2019 Accessed February 1, 2021. Available at: https://www. who.int/news-room/spotlight/ten-threats-to-global-health-in2019.

11. MacDonald NE, 2015. Vaccine hesitancy: definition, scope and determinants. Vaccine 33: 4161-4164.
12. Peretti-Watel $P$, Larson HJ, Ward JK, Schulz WS, Verger $P, 2015$. Vaccine hesitancy: clarifying a theoretical framework for an ambiguous notion. PLoS Currents 7: ecurrents.outbreaks.6844c80ff9f5b273f34c91f71b7fc289. Available at: https://doi.org/10.1371/currents.outbreaks. 6844c80ff9f5b273f34c91f71b7fc289.

13. Aalemi AK, Shahpar K, Mubarak MY, 2020. Factors influencing vaccination coverage among children age 12-23 months in Afghanistan: analysis of the 2015 Demographic and Health Survey. PLoS One 15: e0236955.

14. Adebisi YA, Alaran AJ, Bolarinwa OA, Akande-Sholabi W, LuceroPrisno DE, 2020. When it is available, will we take it? Public perception of hypothetical COVID-19 vaccine in Nigeria. Pan Afr Med J 38: 230

15. Zhong B-L Luo W, Li H-M, Zhang Q-Q, Liu X-G, Li W-T, Li Y, 2020. Knowledge, attitudes, and practices towards COVID-19 among Chinese residents during the rapid rise period of the COVID-19 outbreak: a quick online cross-sectional survey. Int J Biol Sci 16: 1745.

16. Wang J, Jing R, Lai X, Zhang H, Lyu Y, Knoll MD, Fang H, 2020. Acceptance of COVID-19 vaccination during the COVID-19 pandemic in China. Vaccines (Basel) 8: 482.

17. Murphy J et al., 2020. Preparing for a COVID-19 vaccine: identifying and psychologically profiling those who are vaccine hesitant or resistant in two general population samples.

18. Neumann-Böhme S et al., 2020. Once We Have It, Will We Use It? A European Survey on Willingness to be Vaccinated Against COVID-19. Springer

19. Callaghan T, Moghtaderi A, Lueck JA, Hotez PJ, Strych U, Dor A, Fowler EF, Motta M, 2020. Correlates and Disparities of COVID19 Vaccine Hesitancy. Available at SSRN 3667971.

20. Dror AA, Eisenbach N, Taiber S, Morozov NG, Mizrachi M, Zigron A, Srouji S, Sela E, 2020. Vaccine hesitancy: the next challenge in the fight against COVID-19. Eur J Epidemiol 35: 775-779.

21. Mohamed-Hussein AAR, Makhlouf $\mathrm{H}$, Abd El, Aal H, Kholief K, Saad MM, Abdellal DA, 2021. A national survey of potential acceptance of COVID-19 vaccines in healthcare workers in Egypt. medRxiv.

22 Shen, AK, Iv RH, DeWald E, Rosenbaum S, Pisani A, Orenstein W, 2021. Ensuring equitable access to COVID-19 vaccines in the US: current system challenges and opportunities: analysis examines ensuring equitable access to COVID-19 vaccines. Health Aff 40: 62-69.

23. Sallam $M$ et al., 2021. High rates of COVID-19 vaccine hesitancy and its association with conspiracy beliefs: a study in Jordan and Kuwait among other Arab countries. Vaccines (Basel) 9: 42.

24. Lin C, Tu P, Beitsch LM, 2021. Confidence and receptivity for COVID-19 vaccines: a rapid systematic review. Vaccines (Basel) 9: 16.

25. Ipsos MORI, 2021. Global Attitudes: COVID-19 Vaccines. Available at: https://www.ipsos.com/ipsos-mori/en-uk/globalattitudes-to-covid-19-vaccines-wef. Accessed February 10, 2021.

26. Sallam M, 2021. COVID-19 vaccine hesitancy worldwide: a concise systematic review of vaccine acceptance rates. Vaccines (Basel) 9: 160.

27. Lazarus JV, Ratzan SC, Palayew A, Gostin LO, Larson HJ, Rabin K, Kimball S, El-Mohandes A, 2021. A global survey of potential acceptance of a COVID-19 vaccine. Nat Med 27: 225-228. 